\title{
Short-term effects of soil moisture on soil organic carbon decomposition in a coastal wetland of the Yellow River Delta
}

\author{
Wendi Qu $(1) \cdot$ Guangxuan Han · Jian Wang · Juanyong Li $\cdot$ Mingliang Zhao • \\ Wenjun He $\cdot$ Xinge Li $\cdot$ Siyu Wei
}

Received: 28 June 2020/Revised: 14 September 2020/ Accepted: 21 September 2020

(C) Springer Nature Switzerland AG 2020

\begin{abstract}
Soil moisture remarkably influences soil organic carbon (SOC) decomposition and is one of the key variables in ecological models influencing changes in soil carbon (C) storage. However, the mechanisms determining the impact of soil moisture on SOC decomposition in coastal wetlands are poorly understood. We collected and incubated soil samples from a coastal wetland of the Yellow River Delta, China, to investigate the response of SOC decomposition (the sum of $\mathrm{CO}_{2}-\mathrm{C}$ and $\mathrm{CH}_{4}-\mathrm{C}$ ) to soil moisture. Soil samples were incubated at 20\%, 60\%, 100\%, $140 \%$ and $180 \%$ water holding capacity (WHC), respectively. Compared to drought condition (20\% WHC), moist (60\% and 100\% WHC) and flooding (140\% and $180 \%$ WHC) conditions were observed
\end{abstract}

Guest editors: Franziska Eller, Hans Brix, Brian K. Sorrell \& Carlos A. Arias / Wetland ecosystems: functions and use in a changing climate

W. Qu · G. Han $(\bowtie) \cdot$ J. Li $\cdot$ M. Zhao .

W. He $\cdot$ X. Li $\cdot$ S. Wei

CAS Key Laboratory of Coastal Environmental Processes and Ecological Remediation, Yantai Institute of Coastal

Zone Research (YIC), Chinese Academy of Sciences

(CAS), Shandong Key Laboratory of Coastal

Environmental Processes, YICCAS, Yantai 264003,

Shandong, People's Republic of China

e-mail: gxhan@yic.ac.cn

W. Qu · J. Li - W. He

University of Chinese Academy of Sciences,

Beijing 100049, People's Republic of China with significantly higher SOC decomposition, explained by increased soil microbial biomass and altered soil physical parameters ( $\mathrm{pH}$ and electronic conductivity (EC)). Excluding the effect of drought, we found decreased SOC decomposition with increased microbial biomass in flooding conditions compared to moist conditions. Structural equation modeling analysis showed that SOC decomposition and soil $\mathrm{C}$ storage were associated with changes in soil environment and soil microbial biomass resulted from soil moisture variation. This study highlights the importance of soil moisture in soil carbon dynamics, which is enlightening for the evaluation of soil $\mathrm{C}$ cycling with a decline of soil moisture under a warmer climate in coastal wetlands.

Keywords Soil moisture $\cdot$ Soil organic carbon decomposition $\cdot \mathrm{CO}_{2} \cdot \mathrm{CH}_{4} \cdot$ Coastal wetland

W. Qu - G. Han · J. Li · W. He

Center for Ocean Mega-Science, Chinese Academy of Sciences, 7 Nanhai Road, Qingdao 266071, People's Republic of China

\section{J. Wang}

Department of Geography, The Ohio State University, Columbus, $\mathrm{OH} 43210$, USA 


\section{Introduction}

Soil moisture, the amount of water stored in the unsaturated soil zone, is one of the key factors controlling numerous processes in terrestrial ecosystems (Hussain et al., 2011; Biederman et al., 2016; Jia et al., 2016; Vidon et al., 2016). There is mounting evidence that soil moisture controls soil microbial growth and further impacts carbon (C) balance in a variety of ecosystems, including forests and grasslands (Lindroth et al., 1998; Craine \& Gelderman, 2011). Coastal wetlands are reported as one of the most productive ecosystems with large $\mathrm{C}$ stocks and sediment stabilization (Bridgham et al., 2006; Qu et al., 2020). However, the impacts of soil moisture on soil organic carbon (SOC) decomposition and dynamics of soil $\mathrm{C}$ storage remain largely unexplored.

Numerous field studies and incubation experiments have investigated the response of SOC decomposition to soil water availability, leading to inconsistent results within different ecosystems (Dijkstra \& Cheng, 2007; Tao et al., 2018; Shahzad et al., 2019; Li et al., 2020). For example, limited soil moisture in croplands inhibited plant photosynthesis and C fixation (Moyano et al., 2013), which was related to vegetation phenology (Wang et al., 2019). Less carbon stored in plant would further decrease the SOC and SOC decomposition with limited diffusion of substrates for soil microbes (Harper et al., 2005; Chen et al., 2019). However, soil microorganisms with high tolerance to water stress in tropical forests are not as sensitive as microorganisms in arid or semiarid grasslands to soil moisture, leading to different or even opposite effects on SOC decomposition (Moyano et al., 2013; Das et al., 2019). Soil moisture directly affects soil physical and chemical properties, such as increasing electrical conductivity (EC) and decreasing soil $\mathrm{pH}$ (Cardon \& Gage, 2006). Soil water is essential for cellular reactions, inhibiting microbial and enzymatic activity when the soil is drying out (Linn \& Doran, 1984). Previous research reported that microbial activity could cease as soil moisture is extremely insufficient (Skopp et al., 1990; Schjonning et al., 2003). However, if soil becomes waterlogged, the diffusion of oxygen through soil would be restricted (Chu et al., 2018). Flooding conditions are reported to suppress microbial activity and soil organic matter decomposition in forest ecosystems (Heinsch et al., 2004). The metabolic activity of aerobic microorganisms would decrease when soil pore space is filled with water (Cook \& Knight, 2003). Thus, soil moisture regulates soil environment and microbial activity, further modulating soil $\mathrm{C}$ stock. However, the mechanisms determining the effects of soil moisture on SOC decomposition remain poorly explored in coastal wetlands.

Carbon stored in soils is more than thrice the amount of carbon in the atmosphere (Schlesinger \& Andrews, 2000). Meanwhile, SOC decomposition is a key process controlling the balance between carbon loss from soil to the atmosphere and $\mathrm{C}$ sequestration in terrestrial ecosystems (Bond-Lamberty \& Thomson, 2010; Vesterdal et al., 2012). A small change in SOC decomposition could significantly influence the net carbon flux and soil carbon concentration (Davidson \& Janssens, 2006). Large C stocks due to low rates of SOC decomposition make coastal wetlands worth studying, concerning the trend of the rising sea level and fluctuation of soil moisture (Qu et al., 2019; Tian et al., 2019). Given that the ecosystem services of coastal wetlands contribute to human welfare, they are crucial and urgent for coastal protection, erosion and flooding control, fishery and recreation (Barbier et al., 2011). The coastal wetlands of the Yellow River Delta (YRD), located in the interface between terrestrial and ocean ecosystems, are directly associated with regional C sequestration (Han et al., 2018). The soil salinealkaline stress and its consequence has been frequently investigated in the YRD (Guan et al., 2017; Gao et al., 2019). However, the impact of soil moisture on soil $C$ dynamics in coastal wetlands of the YRD is a significant issue with relatively little research. Previous research found that, in floodplain wetlands, optimum moisture of SOC decomposition for topsoils and subsoils was 60\% WHC and 30\% WHC, respectively (Yin et al., 2019). In addition, wetting-drying treatment that cycled between $60 \%$ and $100 \%$ WHC stimulated SOC decomposition in litter-amended alpine wetland soil (Gao et al., 2016). Short-term soil incubation can not only accurately and quantitatively control the soil moisture and temperature but also remove the effects of other environmental factors, such as climate extremes and invasive species, on soil carbon balance. In this study, a 50-day incubation experiment was set up to explore the response of SOC decomposition and soil $\mathrm{C}$ dynamics to soil moisture in a coastal wetland of the YRD, China. The main objectives were (i) to investigate the impact of soil 
moisture on soil properties and microbial biomass in a coastal wetland, (ii) to quantify SOC decomposition under varying soil moisture, and (iii) to explain the potential mechanisms underlying the linkage between soil moisture, soil environment, microbial biomass and SOC decomposition during the incubation.

\section{Materials and methods}

\section{Site description}

The incubated soil was sampled at the mouth of Yellow River in Dongying, in northeast Shandong Province, China $\left(37^{\circ} 36^{\prime} \mathrm{N}, 118^{\circ} 57^{\prime} \mathrm{E}\right)$. The YRD is a major delta among the river deltas of China, and it contains the youngest and largest wetland in the warm temperate regions in China (Xu et al., 2004; Tao et al., 2018). The site is characterized by a warm semi-humid continental monsoon climate with a moderate precipitation and temperature, averaging $560 \mathrm{~mm}$ per year and $12.9^{\circ} \mathrm{C}$ (Han et al., 2018). Due to the seasonal rainfall, nearly $74 \%$ of the precipitation is falling between June and September, high differences of monthly soil moisture have been observed (Chu et al., 2018). The whole area is covered by fluvo-aquic and saline soil due to the high groundwater table and flat terrain, as well as tidal activities (Nie et al., 2009). The dominate plant species are Suaeda maritima subsp. salsa (L.) Soó and Phragmites australis (Cav.) Trin. ex Steud., and the soil texture is mainly sandy clay loam (Guan et al., 2017; Han et al., 2018).

Soil sampling and incubation

In late March 2019, soil samples (0-10 cm depth) were collected with stainless steel shovels, then packed and transported back to the laboratory. We measured soil properties both before and after incubation. The WHC, refers to the ability of a certain soil texture to physically hold water, of soil samples were measured using the single-ring method. Four fresh samples, sieved to a particle size $<2 \mathrm{~mm}$, were taken and stored in a refrigerator $\left(4^{\circ} \mathrm{C}\right)$ to analyze soil microbial biomass carbon (MBC) and microbial biomass nitrogen $(\mathrm{MBN})$. The remaining soil samples were air-dried, four subsamples with the same weight were stored at room temperature to measure soil properties (details of measurement can be seen in
Table 1 Soil properties (mean \pm standard deviation, $n=4$ ) in a coastal wetland in the Yellow River Delta

\begin{tabular}{lr}
\hline Properties & \multicolumn{1}{l}{ Value } \\
\hline $\mathrm{TC}\left(\mathrm{mg} \mathrm{g}^{-1}\right.$ dry soil) & $16.4 \pm 0.2$ \\
$\mathrm{TN}\left(\mathrm{mg} \mathrm{g}^{-1}\right.$ dry soil) & $0.3 \pm 0.1$ \\
$\mathrm{SOC}\left(\mathrm{mg} \mathrm{g}^{-1}\right.$ dry soil) & $4.6 \pm 0.1$ \\
$\mathrm{DOC}\left(\mu \mathrm{g} \mathrm{g}^{-1}\right.$ dry soil) & $91.1 \pm 0.9$ \\
$\mathrm{DN}\left(\mu \mathrm{g} \mathrm{g}^{-1}\right.$ dry soil) & $139.3 \pm 1.0$ \\
$\mathrm{MBC}\left(\mu \mathrm{g} \mathrm{g}^{-1}\right.$ fresh soil) & $33.3 \pm 6.1$ \\
$\mathrm{MBN}\left(\mu \mathrm{g} \mathrm{g}^{-1}\right.$ fresh soil) & $24.2 \pm 5.3$ \\
$\mathrm{pH}(1: 5)$ & $8.1 \pm 0.2$ \\
$\mathrm{EC}\left(\mathrm{ms} \mathrm{cm}^{-1}\right)$ & $6.1 \pm 0.1$ \\
$\mathrm{WHC}_{\mathrm{MAX}}(\%)$ & $11.6 \pm 0.2$ \\
\hline
\end{tabular}

$T C$ total carbon, $T N$ total nitrogen, SOC soil organic carbon, $D O C$ dissolved organic carbon, $D N$ dissolved nitrogen, $M B C$ microbial biomass carbon, $M B N$ microbial biomass nitrogen, $E C$ electronic conductivity, $W H C_{M A X}$ maximum water holding capability

Sect. 2.4). The original soil properties before incubation are shown in Table 1. All other subsamples were homogenized for the incubation experiment.

We added $100 \mathrm{~g}$ of dry soil to every $1000 \mathrm{ml}$ jar. The five treatments with different soil moisture levels were labeled as $20 \%, 60 \%, 100 \%, 140 \%$ and $180 \%$ WHC, and every treatment was repeated four times. In this study, we considered $20 \%$ WHC as drought, $60 \%$ and $100 \%$ WHC as moist and $140 \%$ and $180 \%$ as flooding. During the incubation, we used permeable parafilms to minimize the soil water loss, such as evaporation. Deionized water was added into each jar on the first day, and then water was added every two days with constant weight to maintain the stability of soil moisture. The temperature of incubated room was stably controlled at $22 \pm 2{ }^{\circ} \mathrm{C}$ by air conditioner.

Gases emissions and SOC decomposition

$\mathrm{CO}_{2}$ and $\mathrm{CH}_{4}$ emissions were measured every two days during incubation. We used airtight wooden corks, inserted by a syringe with a three-way valve, to replace parafilms $24 \mathrm{~h}$ before gas sampling, so that daily gas emissions $\left(\mathrm{CO}_{2}\right.$ and $\left.\mathrm{CH}_{4}\right)$ were all stored in the jars. We then directly opened the valve and collected gases into a vacuum tube. Gas samples were measured using gas chromatography (Agilent GC7890, USA). Four empty jars were set up as negative controls to minimize system errors of measurement. In 
this study, the rate of SOC decomposition was the sum of the total rate of $\mathrm{CH}_{4}-\mathrm{C}$ emissions and $\mathrm{CO}_{2}-\mathrm{C}$ emissions (Qu et al., 2020):

$\sum_{t=d 1}^{d 2} \mathrm{SOC}_{\mathrm{d}}=\sum_{t=d 1}^{d 2} \mathrm{CH}_{4}-\mathrm{C}+\sum_{t=d 1}^{d 2} \mathrm{CO}_{2}-\mathrm{C}$

where $\mathrm{SOC}_{\mathrm{d}}$ is the rate of SOC decomposition, $\mathrm{d} 1$ and $\mathrm{d} 2$ represent the first and last day of incubation, respectively.

\section{Soil physical and chemical properties}

Soil samples and deionized water were mixed at a ratio of $1: 5$ and then shaken for $1 \mathrm{~h}$, the mixture was centrifuged $(6000 \mathrm{rpm})$ for $25 \mathrm{~min}$ and followed by $0.45 \mu \mathrm{m}$ vacuum filtration. After this pretreatment, dissolved organic carbon (DOC), MBC, MBN were measured on a Shimadzu TOC analyzer (TOC$\mathrm{VCPH})$. MBC and MBN were measured by the chloroform-fumigation extraction method. Total carbon (TC) and total nitrogen (TN) were measured on an elemental analyzer (Vario MACRO cube, Elementar Analysensysteme, Germany). We removed total inorganic carbon with hydrochloric acid $\left(\mathrm{HCl}, 1 \mathrm{~mol}^{-1}\right)$ from the samples, and then measured SOC on the elemental analyzer. The electrical conductivity (EC) and $\mathrm{pH}$ were measured in a ratio of 1:5 (w/v) soil and water suspension potentiometrically. $\mathrm{EC}$ and $\mathrm{pH}$ were measured using a portable conductivity and $\mathrm{pH}$ meter, respectively.

\section{Statistical analyses}

One-way ANOVA was used to analyze the difference of soil properties and the rate of SOC decomposition under the different treatments. Significance was set at $P<0.05$. We applied Pearson correlation analysis to determine the correlation between soil properties and SOC decomposition of incubation. Structural equation modeling (SEM) was used to test direct and indirect linkage between soil moisture and SOC decomposition. In this study, we assumed that soil moisture adjusts SOC decomposition via regulating soil environment $(\mathrm{pH}$ and $\mathrm{EC})$ and soil microbial biomass (MBC and $\mathrm{MBN}$ ), further impacting soil $\mathrm{C}$ (SOC, DOC, TC) and $\mathrm{N}(\mathrm{DN}, \mathrm{TN})$ storage. The criteria for SEM evaluation, such as Root Mean Square Error of Approximation (RMSEA), $\chi^{2} / \mathrm{df}$ and Bentler-Bonett
Normed Fit Index (NFI), were adopted (Hair et al., 2017). In this study, partial least square method was used in SEM to predict complexly predictive path models as the sample size was relatively small $(<100)$ (Wong, 2013). SEMs analyses were carried out using the AMOS 23 (IBM, Chicago, IL, USA).

\section{Results}

$\mathrm{CO}_{2}$ and $\mathrm{CH}_{4}$ emissions

During the incubation, we observed distinctly different daily emissions dynamics and cumulative emissions of $\mathrm{CO}_{2}$ and $\mathrm{CH}_{4}$ in the different soil moisture treatments (Fig. 1). $\mathrm{CO}_{2}$ emissions showed similar pattern in moist (60\% and 100\% WHC) and flooding ( $140 \%$ and $180 \%$ WHC) treatments, with comparably high daily $\mathrm{CO}_{2}$ emissions in the early incubation that decreased over time (Fig. 1a). Sample soils in moist conditions generally released more than $23 \%$ of $\mathrm{CO}_{2}$ than in flooding conditions $(P<0.05$, Fig. 2a). Drought conditions (20\% WHC) inhibited $\mathrm{CO}_{2}$ emissions during the whole incubation period. $\mathrm{CH}_{4}$ emissions showed similar trend under different soil moisture, with a linear increase within the first week and then stable emissions until the end of incubation (Fig. 1b). After a month of incubation (day 30), drought conditions led to slight decrease of $\mathrm{CH}_{4}$ emissions compared to moist and flooding conditions. Daily average $\mathrm{CH}_{4}$ emissions during the whole incubation period showed no significant difference under different water conditions (Fig. 2b).

Soil moisture-induced changes in soil properties and SOC decomposition

Soil moisture significantly changed soil properties and SOC decomposition through the incubation period (Fig. 3). Microbial biomass (MBC and MBN) increased with the soil moisture. MBC or MBN in the $180 \%$ WHC soil was nearly 18 and 3 times of MBC and $\mathrm{MBN}$, respectively, in the $20 \%$ WHC soil $(P<0.05$, Fig. $3 \mathrm{c}$ and $\mathrm{d})$. The strongest decrease of soil EC, along with the increase of $\mathrm{pH}$, was observed in drought conditions (Fig. 3e, i). The highest value of soil $\mathrm{C}$ and $\mathrm{N}$ pools (TC, TN, SOC, DOC, DN) was observed in drought conditions, and the values decreased as soil moisture increased (Fig. 3a, b, f, g 

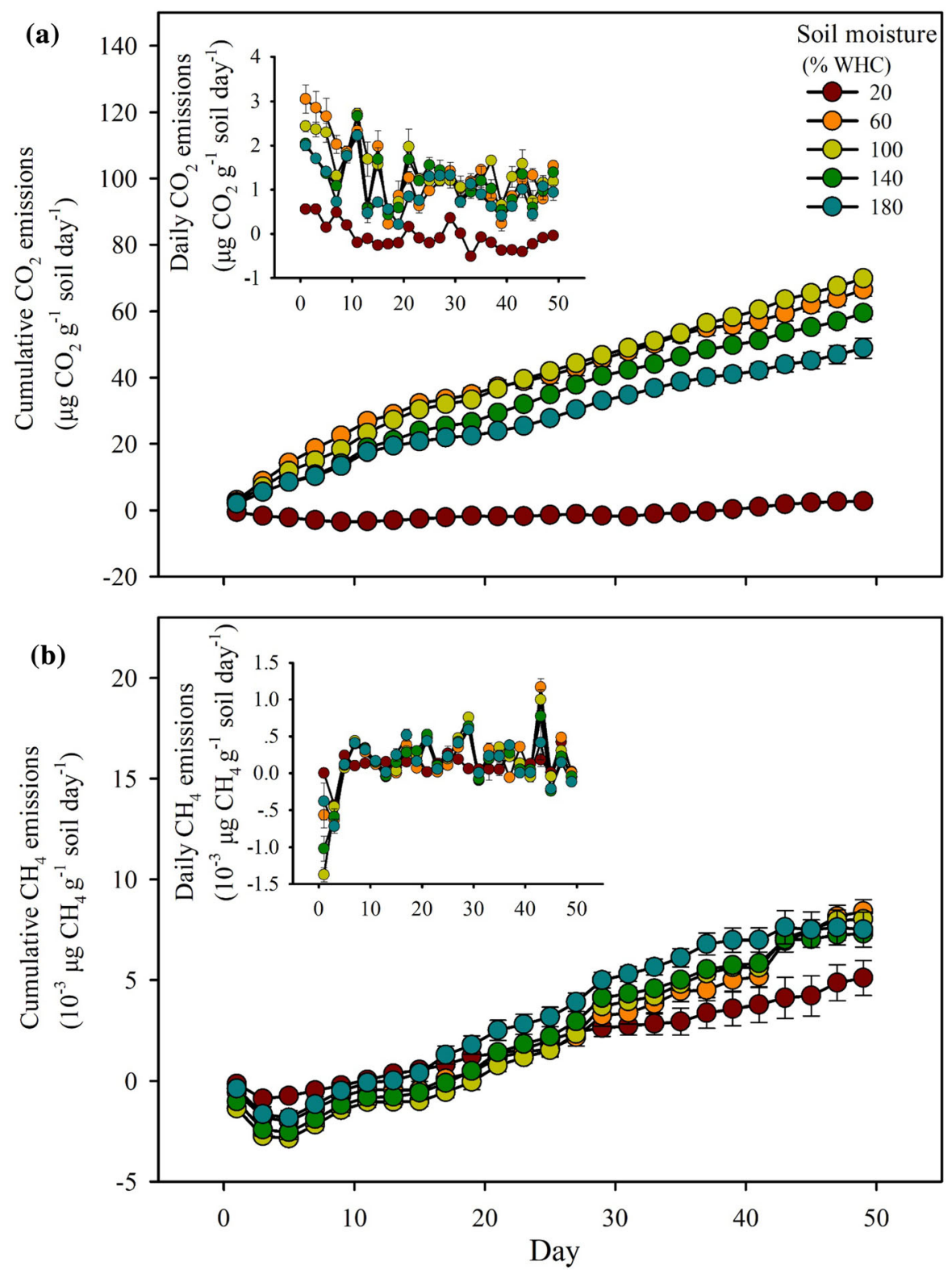

Fig. 1 Cumulative emissions of $\mathrm{CO}_{2}$ and $\mathrm{CH}_{4}$ during the 50-day incubation period of soil samples with 20\%, 60\%, 100\%, $140 \%$ and $180 \%$ water holding capacity (WHC). The error bars

and $\mathrm{h}$ ). The pattern of SOC decomposition was similar to $\mathrm{CO}_{2}$ emissions under different water conditions, with the highest value in moist conditions, followed by flooding conditions and drought conditions (Fig. 3j). indicate the standard deviations of four measurements $(n=4)$. The subgraph represents daily $\mathrm{CO}_{2}$ and $\mathrm{CH}_{4}$ emissions for different treatments

Impact of soil moisture on soil properties and SOC decomposition

Pearson correlation analysis showed correlations between soil environment, soil $\mathrm{C}$ stock and gas emissions under varying soil moisture (drought, moist and flooding conditions: Table 2; moist and flooding conditions: Table 3). Negative correlations were 
observed between SOC, DOC, DN, and $\mathrm{CO}_{2}$ emissions $(P<0.01)$. EC was positively correlated with $\mathrm{CO}_{2}$ and $\mathrm{CH}_{4}$ emissions, with a coefficient $\mathrm{r}$ of 0.81 $(P<0.01)$ and $0.45(P<0.05)$, respectively. Negative correlations were also found between $\mathrm{pH}$ and MBC and MBN (Table 2). Excluding the effect of drought, we found opposite correlation between EC and $\mathrm{CO}_{2}$, shifting from positive (Table 2) to negative (Table 3). Similarly, positive correlation between $\mathrm{MBC}$ and $\mathrm{pH}$ and negative correlation between
Fig. 3 Effects of soil moisture $(20 \%, 60 \%, 100 \%, 140 \%$ and $180 \%$ WHC) on soil properties and SOC decomposition through 50 -day incubation. TC total carbon, SOC soil organic carbon, $M B C$ microbial biomass carbon, $M B N$ microbial biomass nitrogen, $T N$ total nitrogen, $D O C$ dissolved organic carbon, $D N$ dissolved nitrogen, $E C$ electricity conductance. Different lower case letters represent significant differences $(P<0.05)$

MBC and SOC decomposition were observed under moist and flooding conditions (Table 3).

SEM analysis was performed to analyze the potential mechanisms and underlying differences among
Fig. 2 Daily average a $\mathrm{CO}_{2}$ and $\mathbf{b} \mathrm{CH}_{4}$ emissions during a 50-day incubation period of soil samples with moisture of $20 \%, 60 \%$, $100 \%, 140 \%$ and $180 \%$ water holding capacity (WHC). Different lower case letters represent a significant difference $(P<0.05)$

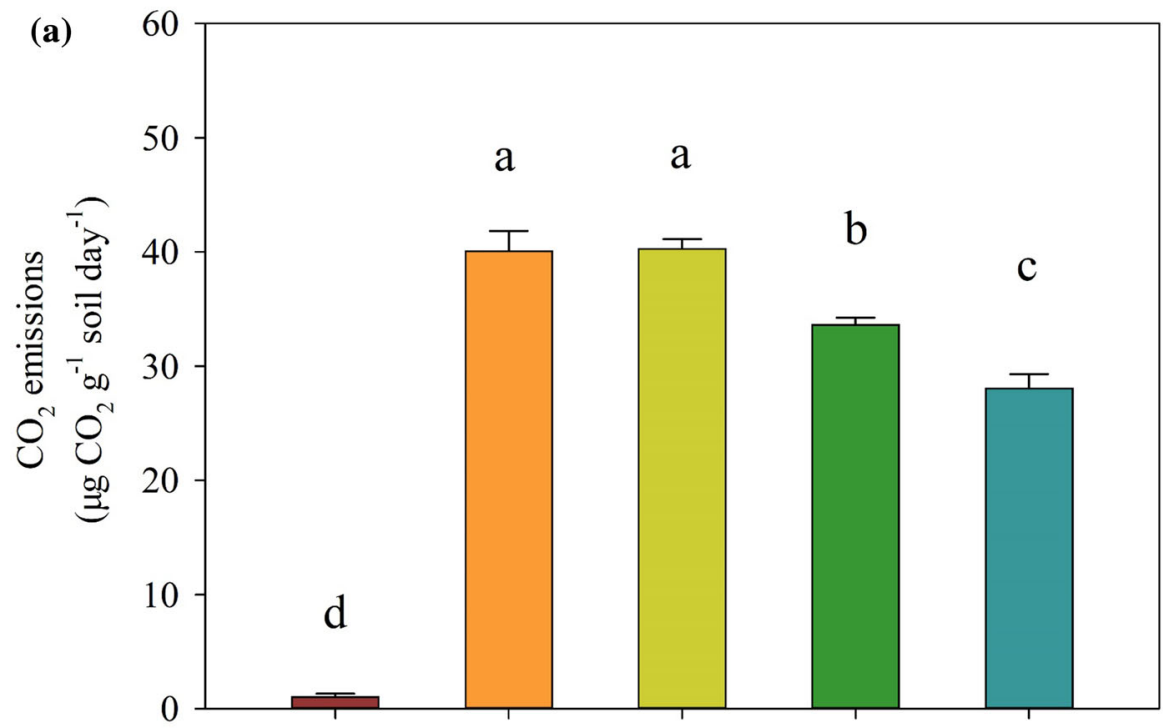

(b)

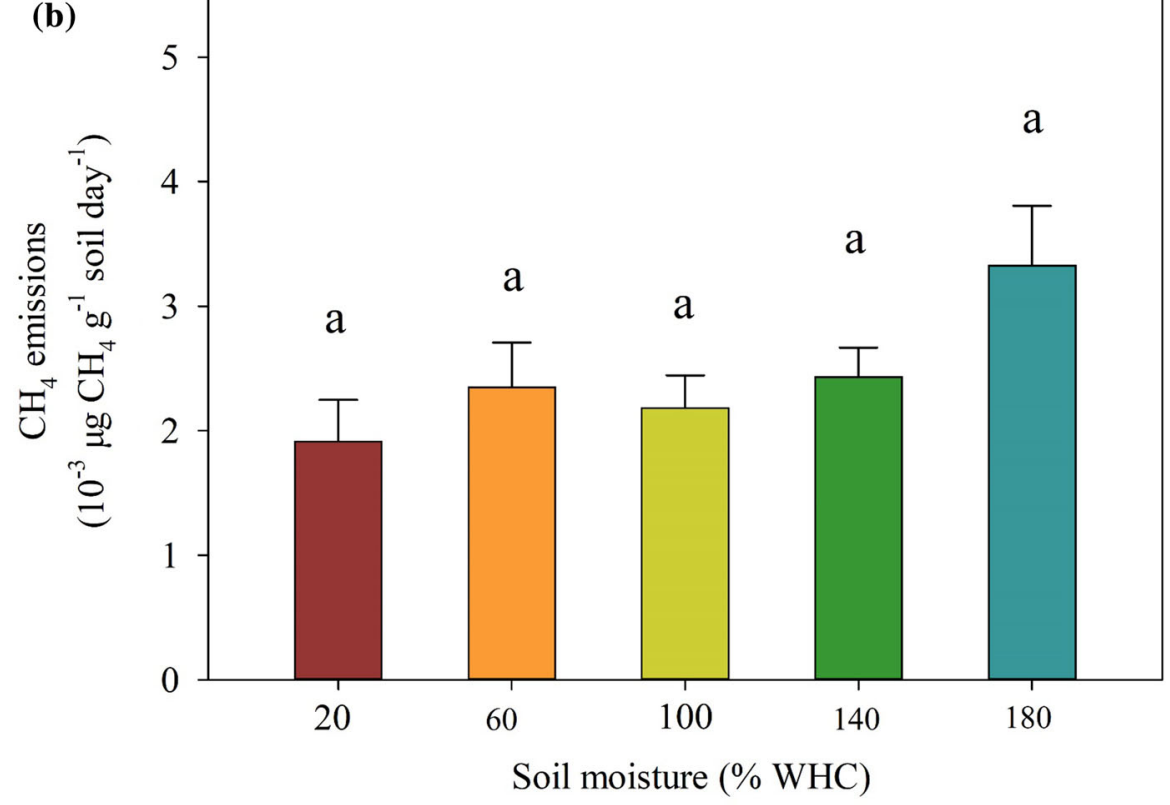



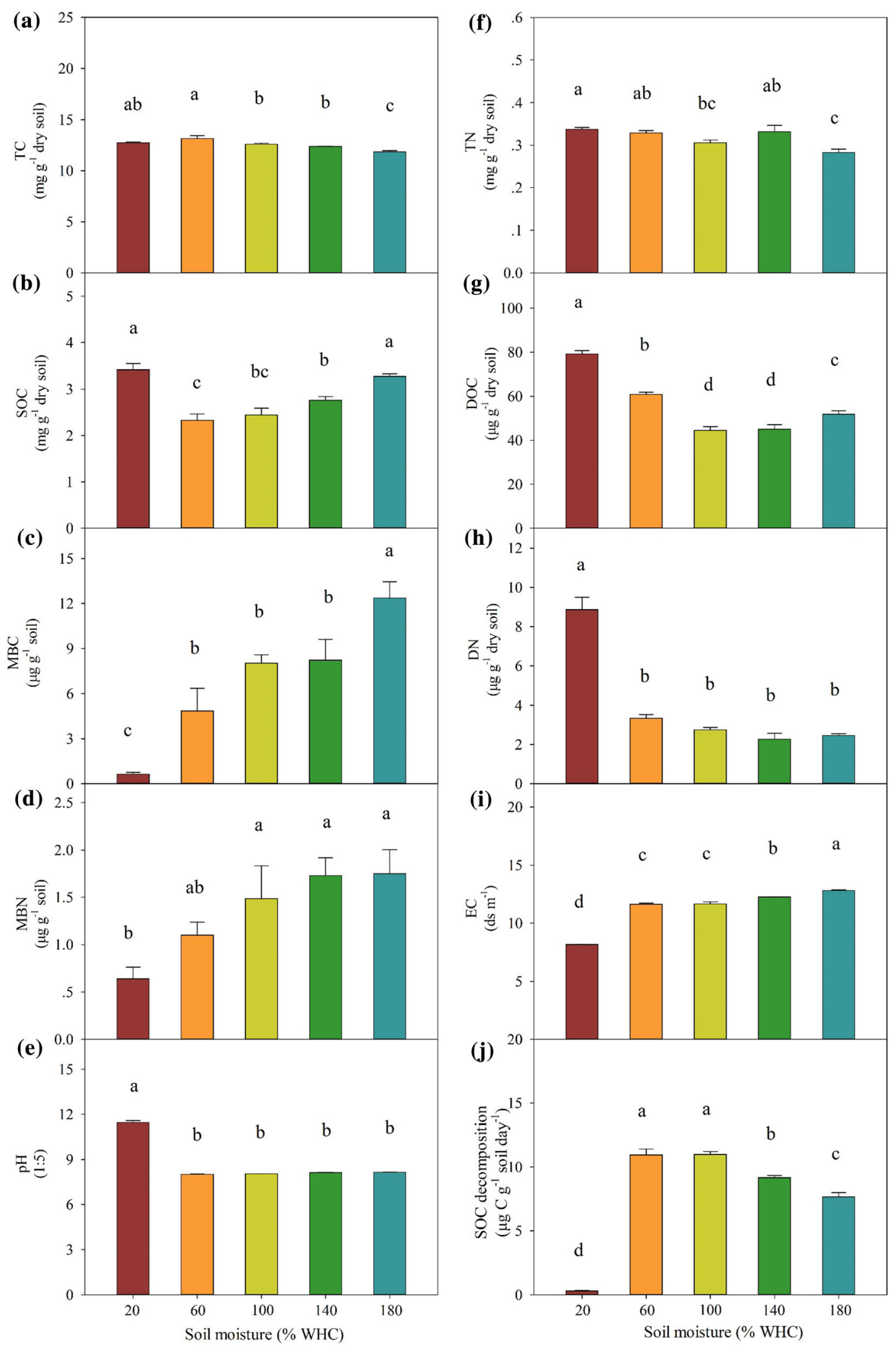
Fig. 4 Structural equation model (SEM) analysis, a including all levels of moisture $(20 \%, 60 \%, 100 \%$, $140 \% 180 \%$ of WHC),

b excluding drought condition (20\% of WHC), describing the effect of soil moisture on soil environment ( $\mathrm{pH}$ and $\mathrm{EC}$ ), soil microbial biomass (MBC and MBN), SOC decomposition and soil $\mathrm{C}$ (SOC, DOC, TC) and N (DN, TN) pools. $S M$ soil moisture, $E C$ electrical conductivity, $M B C$ microbial biomass carbon, $M B N$ microbial biomass nitrogen, $S O C$ soil organic carbon, $D O C$ dissolved organic carbon, $S O C_{d}$ SOC decomposition, $T C$ total carbon, $D N$ dissolved nitrogen, $T N$ total nitrogen. Path coefficients (correlation coefficients) along arrows are standardized by the mean of each parameter. Numbers on the arrows are standardized direct path coefficients. Red arrow lines indicate positive effects, and blue arrow lines indicate negative effects.

The width of the arrows is proportional to the strength of the relationship, and the numbers adjacent to arrows are standardized path coefficients. Percentages close to variables refer to the variance accounted for by the model $\left(R^{2}\right) . * P<0.05$, $* * P<0.01, * * * P<0.001$
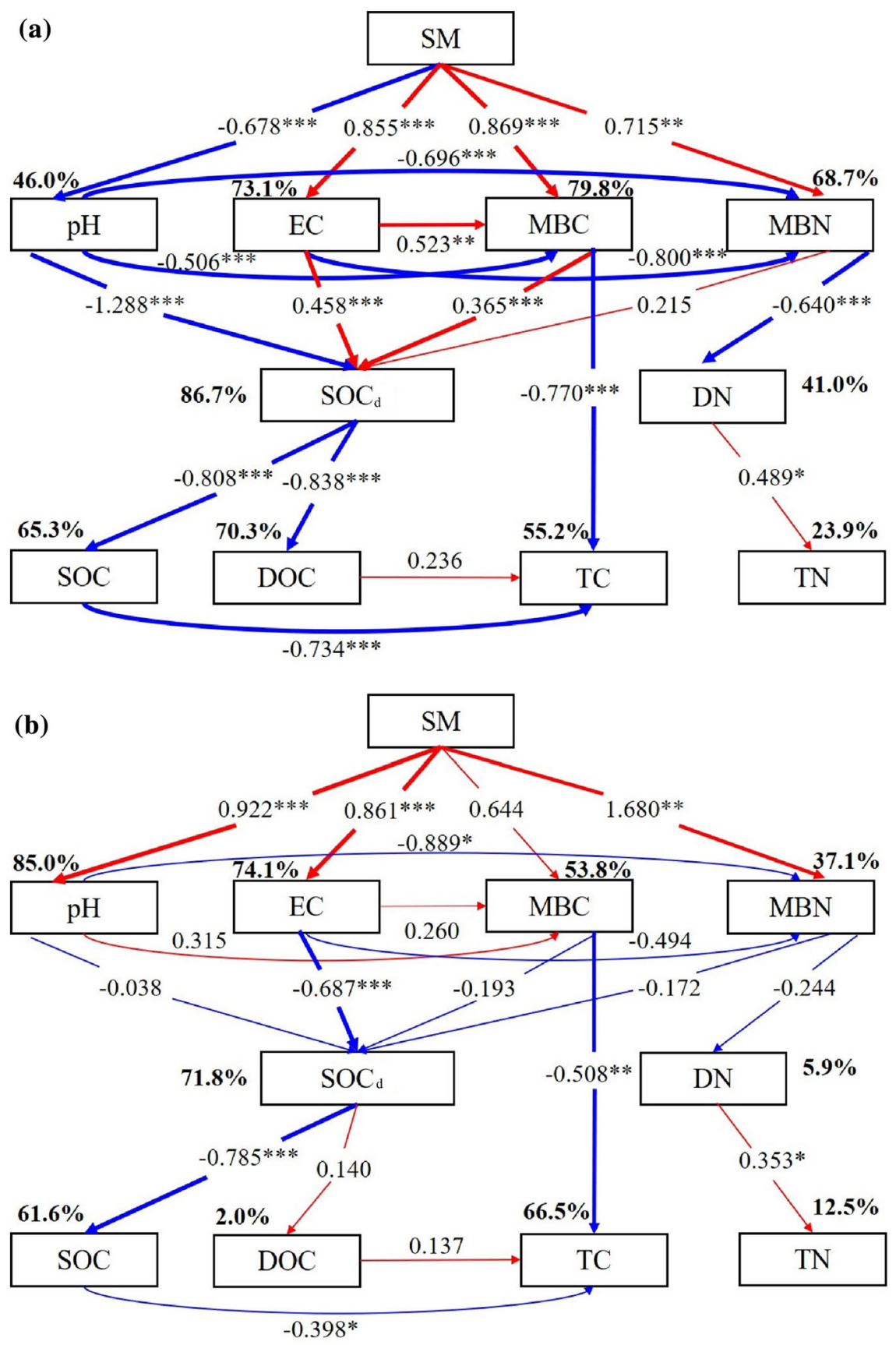

soil moisture, soil environment, soil $\mathrm{C}$ storage and SOC decomposition under drought, moist and flooding conditions (Fig. 4a). The significance criteria of SEM were met, with RMSEA, $\chi^{2} / \mathrm{df}$ and NFI of $0.094,3.028$ and 0.897 , respectively. The model explained $46 \%$ of the variance of soil $\mathrm{pH}, 73.1 \%$ for $\mathrm{EC}, 79.8 \%$ for MBC, $68.7 \%$ for $\mathrm{MBN}$ and $86.7 \%$ for SOC decomposition. Microbial biomass was positively driven by increased soil moisture, leading to stimulated SOC decomposition, further lowering SOC and DOC. Consistent with the results from Pearson correlation analysis, EC was positively correlated with soil moisture and $\mathrm{MBC}$, directly and positively associated with SOC decomposition. Excluding the 


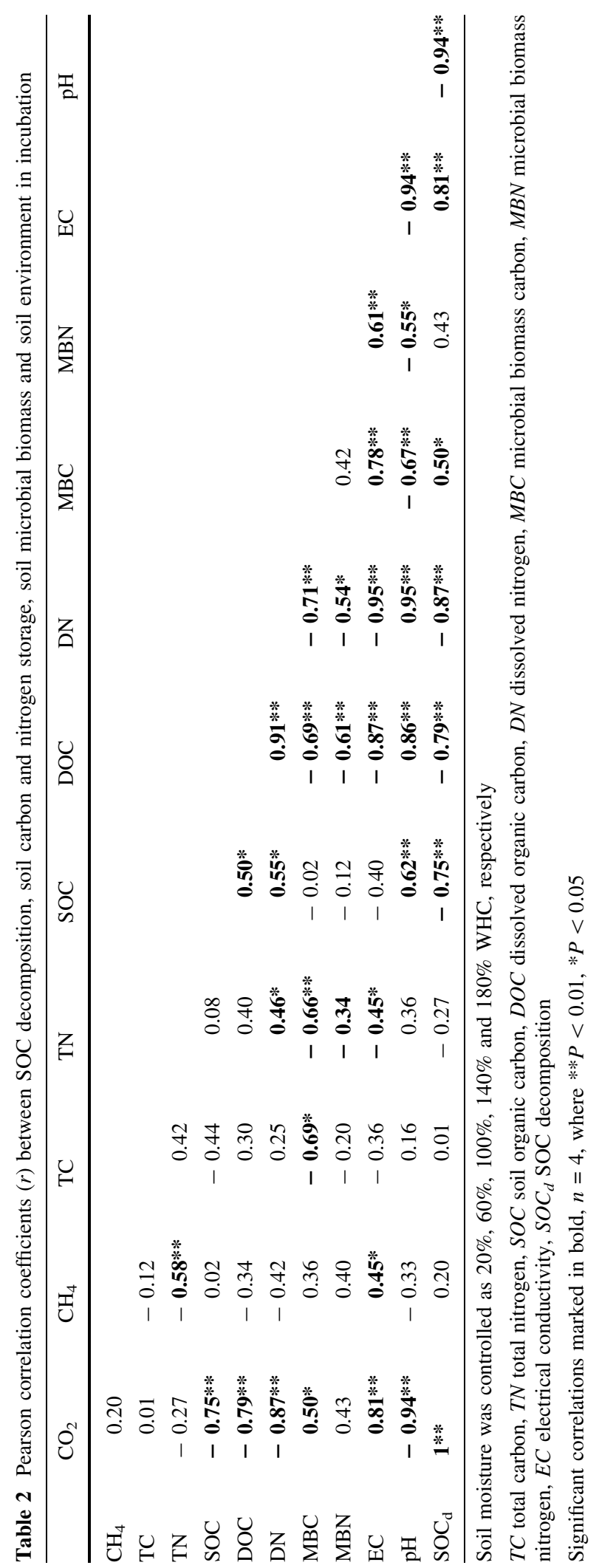


Table 3 Pearson correlation coefficients $(r)$ between soil organic carbon decomposition, soil carbon and nitrogen storage, soil microbial biomass and soil environment in incubation

\begin{tabular}{|c|c|c|c|c|c|c|c|c|c|c|c|}
\hline & $\mathrm{CO}_{2}$ & $\mathrm{CH}_{4}$ & $\mathrm{TC}$ & $\mathrm{TN}$ & SOC & DOC & $\mathrm{DN}$ & MBC & MBN & $\mathrm{EC}$ & $\mathrm{pH}$ \\
\hline $\mathrm{CH}_{4}$ & -0.32 & & & & & & & & & & \\
\hline $\mathrm{TC}$ & $0.60^{*}$ & 0.08 & & & & & & & & & \\
\hline $\mathrm{TN}$ & 0.28 & $-0.52 *$ & 0.40 & & & & & & & & \\
\hline SOC & $-0.78 * *$ & 0.39 & $-0.72 * *$ & -0.23 & & & & & & & \\
\hline DOC & 0.14 & -0.08 & 0.28 & 0.15 & -0.05 & & & & & & \\
\hline $\mathrm{DN}$ & 0.43 & -0.37 & 0.48 & 0.35 & -0.23 & $0.75^{* * *}$ & & & & & \\
\hline MBC & $-0.60^{*}$ & 0.21 & $-0.78^{* *}$ & $-0.62 *$ & $0.68 * *$ & -0.27 & -0.39 & & & & \\
\hline MBN & -0.38 & 0.34 & -0.09 & -0.21 & 0.29 & -0.32 & -0.24 & 0.04 & & & \\
\hline $\mathrm{EC}$ & $-0.87 * *$ & $0.51^{*}$ & $-0.60^{*}$ & -0.35 & $0.66^{* *}$ & -0.28 & $-0.61^{*}$ & $0.53^{*}$ & 0.28 & & \\
\hline $\mathrm{pH}$ & $-0.75^{* *}$ & 0.33 & $-0.88^{* *}$ & -0.43 & $0.73^{* *}$ & -0.33 & $-0.66^{* *}$ & $0.71 * *$ & 0.29 & $0.76^{* *}$ & \\
\hline $\mathrm{SOC}_{\mathrm{d}}$ & $1^{* *}$ & -0.32 & $0.60^{*}$ & 0.28 & $-0.78^{* *}$ & 0.14 & 0.43 & $-0.60^{*}$ & 0.38 & $0.87 * *$ & $-0.75^{* *}$ \\
\hline
\end{tabular}

Soil moisture was controlled as 60\%, 100\%, 140\% and 180\% WHC, respectively. Drought condition (20\% WHC) was excluded $T C$ total carbon, $T N$ total nitrogen, $S O C$ soil organic carbon, $D O C$ dissolved organic carbon, $D N$ dissolved nitrogen, $M B C$ microbial biomass carbon, $M B N$ : microbial biomass nitrogen, $E C$ electrical conductivity, $S O C_{d}$ SOC decomposition

Significant correlations marked in bold, $n=4$, where $* * P<0.01, * P<0.05$

effect of drought (Fig. 4b), the significance criteria of SEM were also met, with RMSEA, $\chi^{2} / \mathrm{df}$ and NFI of $0.098,3.599$ and 0.852 , respectively. $71.8 \%$ variance of SOC decomposition was explained, negatively related to EC. Increased soil moisture increased $\mathrm{pH}$ and further inhibited SOC decomposition under moist and flooding conditions.

\section{Discussion}

Soil moisture conditions (drought, moist and flooding) could impact soil physical and chemical properties and profoundly alter C fluxes (Biederman et al., 2016; Jia et al., 2016). In this study, different soil moisture significantly changed soil physical properties ( $\mathrm{pH}$ and $\mathrm{EC}$ ), and microbial biomass (MBC and $\mathrm{MBN}$ ) during an incubation period (Fig. 3e, g, h and i). Our results confirmed the significant correlation between $\mathrm{pH}$ and microorganisms. Soil $\mathrm{pH}$, directly adjusted by soil moisture, could be a primary factor controlling microbial activity, for example, phenol oxidase which is sensitive to $\mathrm{pH}$ associated with the rate-limiting step in decomposition (Sinsabaugh et al., 2008). The increase of soil moisture negatively affected $\mathrm{pH}$, indicating that higher moisture could alleviate soil drought and reduce soil $\mathrm{pH}$ (Table 2) in coastal wetlands. In addition, increased moisture could directly stimulate soil microbes including extracellular enzymes (Schimel et al., 1999; Davidson \& Janssens, 2006). Drought reduces the thickness of soil water films, thus inhibiting diffusion of extracellular enzymes and soluble organic-C substrates and lowering substrate availability at reaction microsites (Davidson \& Janssens, 2006). When soil moisture is higher than the optimum point, increased water availability can suppress microbial activity (Linn \& Doran, 1984; Horz et al., 2004). Flooding slows oxygen diffusion to decomposition reaction sites, often allowing only anaerobic decomposition, which includes fewer and generally slower degrading enzymatic pathways (Davidson \& Janssens, 2006). The relationship between soil moisture and microbial biomass can be characterized as a curve that has a peak of optimal water availability. However, we observed a significant and positive correlation between soil moisture and MBC (Fig. 3c), indicating that microorganisms might be affected less by osmotic stress comparing to the diffusion of substrates (Manzoni et al., 2012).

Overall, SEM analysis revealed that increased MBC under wetter conditions stimulated SOC decomposition under varying soil moisture (drought, moist and flooding, Fig. 4a), however, had a negative albeit 
non-significant impact on SOC decomposition when drought conditions were excluded (Fig. 4b). The possible reason is that the relationship between $\mathrm{MBC}$ and SOC decomposition is co-regulated by soil oxygen content and soil organic matter (SOC and DOC) (Moyano et al., 2013). Under flooding conditions, larger number of microorganisms may need more oxygen to decompose the SOC, and logged water with limited oxygen availability constrained the rate of SOC decomposition. Previous studies have illustrated that low SOC decomposition under flooding conditions could be associated with physical protection, inhibiting diffusion of catabolites and interactivity with the surface of soil organic matter (Six et al., 2002; Kleber et al., 2015; Zhao et al., 2020). Interestingly, the correlation between EC and SOC decomposition with all treatments is opposite to the correlation that removing the drought conditions (Tables 2 and 3). One potential reason is related to the balance of soil substrate availability and ionic stress. Compared to drought conditions, increased soil moisture significantly stimulated the movement and availability of soil substrate (SOC and DOC, Fig. 3) and further promoted the rate of SOC decomposition (Liu et al., 2017). However, if soil water availability surpassed the optimum without considering drought conditions, high EC would lead to ionic stress, suppressing the process of decomposition (Qu et al., 2019).

Given that the incubation hindered the $\mathrm{C}$ input as no additional substrate was provided, increased SOC decomposition directly reduced soil $\mathrm{C}$ storage, with a negative correlation between SOC decomposition and SOC, DOC, as well as TC (Fig. 4a, b). This study therefore confirms that soil moisture, as an important driver, controls soil environment and microbial biomass and activities, regulates SOC decomposition and soil $\mathrm{C}$ stock and further impacts soil organic matter accumulation and soil composition. This study stressed the importance of soil moisture in soil carbon dynamics, i.e., SOC decomposition and soil $\mathrm{C}$ storage, which is enlightening for the evaluation of soil $\mathrm{C}$ cycling with a decreasing trend of soil moisture due to climate warming.

\section{Conclusions}

Our results suggested that alleviation of water stress (drought, 20\% WHC) would significantly increase
SOC decomposition and consume more of the soil $\mathrm{C}$ stock. Increased water availability directly increased soil EC and microbial biomass (MBC and MBN) and alleviated soil alkalization, further stimulating the rate of SOC decomposition during incubation. However, excluding the effect of drought, we found opposite effect of increasing moisture on SOC decomposition under moist (60\% WHC) and flooding (140\% and $180 \%$ WHC) conditions, suggesting that excessive water would inhibit SOC decomposition via suppressing microbial biomass ( $\mathrm{MBC}$ and $\mathrm{MBN}$ ) and shifting soil environment ( $\mathrm{pH}$ and $\mathrm{EC}$ ) in coastal wetlands. This study indicated that soil moisture is an important factor that controls the process of SOC decomposition in coastal wetlands, and contributes to a better understanding of mechanistic processes surrounding moisture-associated soil $\mathrm{C}$ dynamics under climate change.

Acknowledgements This research was funded by the Strategic Priority Research Program of the Chinese Academy of Sciences (XDA23050202), the National Natural Science Foundation of China (Grant No. 41671089) and Forestry Science and Technology Innovation Project of Shandong Province (Grant No. 2019LY006). We are grateful for the support from Yellow River Delta Ecological Research Station of Coastal Wetland, CAS.

\section{References}

Barbier, E. B., S. D. Hacker, C. Kennedy, E. W. Koch, A. C. Stier \& B. R. Silliman, 2011. The value of estuarine and coastal ecosystem services. Ecological Monographs 81(2): 169-193.

Biederman, J. A., R. L. Scott, M. L. Goulden, R. Vargas, M. E. Litvak, T. E. Kolb, E. A. Yepez, W. C. Oechel, P. D. Blanken, T. W. Bell, J. Garatuza-Payan, G. E. Maurer, S. Dore \& S. P. Burns, 2016. Terrestrial carbon balance in a drier world: the effects of water availability in southwestern North America. Global Change Biology 22(5): 1867-1879.

Bond-Lamberty, B. \& A. Thomson, 2010. Temperature-associated increases in the global soil respiration record. Nature 464: 579-582.

Bridgham, S. D., J. P. Megonigal, J. K. Keller, N. B. Bliss \& C. Trettin, 2006. The carbon balance of North American wetlands. Wetlands 26: 889-916.

Cardon, Z. G. \& D. J. Gage, 2006. Resource exchange in the rhizosphere: molecular tools and the microbial perspective. Annual Review of Ecology Evolution and Systematics 37: 459-488.

Chen, F., G. Y. Yan, Y. J. Xing, J. H. Zhang, Q. G. Wang, H. L. Wang, B. B. Huang, Z. M. Hong, G. H. Dai, X. B. Zheng $\&$ T. Liu, 2019. Effects of $\mathrm{N}$ addition and precipitation 
reduction on soil respiration and its components in a temperate forest. Agricultural and Forest Meteorology 271: 336-345.

Chu, X. J., G. X. Han, Q. H. Xing, J. Y. Xia, B. Y. Sun, J. B. Yu \& D. J. Li, 2018. Dual effect of precipitation redistribution on net ecosystem $\mathrm{CO}_{2}$ exchange of a coastal wetland in the Yellow River Delta. Agricultural and Forest Meteorology 249: 286-296.

Cook, F. J. \& J. H. Knight, 2003. Oxygen transport to plant roots: modeling for physical understanding of soil aeration. Soil Science Society of America Journal 67: 20-31.

Craine, J. M. \& T. M. Gelderman, 2011. Soil moisture controls on temperature sensitivity of soil organic carbon decomposition for a mesic grassland. Soil Biology \& Biochemistry 43(2): 455-457.

Das, S., B. K. Richards, K. L. Hanley, L. Krounbi, M. F. Walter, M. T. Walter, T. S. Steenhuis \& J. Lehmann, 2019. Lower mineralizability of soil carbon with higher legacy soil moisture. Soil Biology \& Biochemistry 130: 94-104.

Davidson, E. A. \& I. A. Janssens, 2006. Temperature sensitivity of soil carbon decomposition and feedbacks to climate change. Nature 440: 165-173.

Dijkstra, F. A. \& W. X. Cheng, 2007. Moisture modulates rhizosphere effects on $\mathrm{C}$ decomposition in two different soil types. Soil Biology \& Biochemistry 39: 2264-2274.

Gao, J., J. Feng, X. Zhang, F. H. Yu, X. Xu \& Y. Kuzyakov, 2016. Drying-rewetting cycles alter carbon and nitrogen mineralization in litter-amended alpine wetland soil. Catena 145: 285-290.

Gao, Y., S. N. Sun, F. Xing, X. M. Mu \& Y. G. Bai, 2019. Nitrogen addition interacted with salinity-alkalinity to modify plant diversity, microbial PLFAs and soil coupled elements: a 5-year experiment. Applied Soil Ecology 137: 78-86.

Guan, B., J. B. Yu, A. X. Hou, G. X. Han, G. M. Wang, F. Z. Qu, J. B. Xia \& X. H. Wang, 2017. The ecological adaptability of Phragmites australis to interactive effects of water level and salt stress in the Yellow River Delta. Aquatic Ecology 51: 107-116.

Hair, J. F., C. L. Hollingsworth, A. B. Randolph \& A. Y. L. Chong, 2017. An updated and expanded assessment of PLS-SEM in information systems research. Industrial Management \& Data Systems 117(3): 442-458.

Han, G. X., B. Y. Sun, X. J. Chu, Q. H. Xing, W. M. Song \& J. Y. Xia, 2018. Precipitation events reduce soil respiration in a coastal wetland based on four-year continuous field measurements. Agricultural and Forest Meteorology 256: 292-303.

Harper, C. W., J. M. Blair, P. A. Fay, A. K. Knapp \& J. D. Carlisle, 2005. Increased rainfall variability and reduced rainfall amount decreases soil $\mathrm{CO}_{2}$ flux in a grassland ecosystem. Global Change Biology 11(2): 322-334.

Heinsch, F. A., J. L. Heilman, K. J. McInnes, D. R. Cobos, D. A. Zuberer \& D. L. Roelke, 2004. Carbon dioxide exchange in a high marsh on the Texas Gulf Coast: effects of freshwater availability. Agricultural and Forest Meteorology 125: 159-172.

Horz, H. P., A. Barbrook, C. B. Field \& B. J. M. Bohannan, 2004. Ammonia-oxidizing bacteria respond to multifactorial global change. Proceedings of the National Academy of Sciences of the United States of America 101(42): 15136-15141.

Hussain, M. Z., T. Grunwald, J. D. Tenhunen, Y. L. Li, H. Mirzae, C. Bernhofer, D. Otieno, N. Q. Dinh, M. Schmidt, M. Wartinger \& K. Owen, 2011. Summer drought influence on $\mathrm{CO}_{2}$ and water fluxes of extensively managed grassland in Germany. Agriculture Ecosystems \& Environment 141(1-2): 67-76.

Jia, X., T. S. Zha, J. N. Gong, B. Wang, Y. Q. Zhang, B. Wu, S. G. Qin \& H. Peltola, 2016. Carbon and water exchange over a temperate semi-arid shrubland during three years of contrasting precipitation and soil moisture patterns. Agricultural and Forest Meteorology 228-229: 120-129.

Kleber, M., K. Eusterhues, M. Keiluweit, C. Mikutta, R. Mikutta \& P. S. Nico, 2015. Mineral-organic associations: formation, properties, and relevance in soil environments. Advances in Agronomy 130: 1-140.

Li, J. Y., W. D. Qu, G. X. Han, F. Lu, Y. F. Zhou, W. M. Song, B. H. Xie \& F. Eller, 2020. Effects of drying-rewetting frequency on vertical and lateral loss of soil organic carbon in a tidal salt marsh. Wetlands. https://doi.org/10.1007/ s13157-020-01286-5.

Lindroth, A., A. Grelle \& A. S. Moren, 1998. Long-term measurements of boreal forest carbon balance reveal large temperature sensitivity. Global Change Biology 4(4): 443-450.

Linn, D. M. \& J. W. Doran, 1984. Effect of water-filled porespace on carbon-dioxide and nitrous-oxide production in tilled and nontilled soils. Soil Science Society of America Journal 48: 1267-1272.

Liu, X., A. Ruecker, B. Song, J. Xing, W. H. Conner \& A. T. Chow, 2017. Effects of salinity and wet-dry treatments on $\mathrm{C}$ and $\mathrm{N}$ dynamics in coastal-forested wetland soils: implications of sea level rise. Soil Biology \& Biochemistry 112: 56-67.

Manzoni, S., J. P. Schimel \& A. Porporato, 2012. Responses of soil microbial communities to water stress: results from a meta-analysis. Ecology 93(4): 930-938.

Moyano, F. E., S. Manzoni \& C. Chenu, 2013. Responses of soil heterotrophic respiration to moisture availability: an exploration of processes and models. Soil Biology \& Biochemistry 59: 72-85.

Nie, M., X. D. Zhang, J. Q. Wang, L. F. Jiang, J. Yang, Z. X. Quan, X. H. Cui, C. M. Fang \& B. Li, 2009. Rhizosphere effects on soil bacterial abundance and diversity in the Yellow River Deltaic ecosystem as influenced by petroleum contamination and soil salinization. Soil Biology \& Biochemistry 41(12): 2535-2542.

Qu, W. D., J. Y. Li, G. X. Han, H. T. Wu, W. M. Song \& X. S. Zhang, 2019. Effect of salinity on the decomposition of soil organic carbon in a tidal wetland. Journal of Soils and Sediments 19: 609-617.

Qu, W. D., G. X. Han, F. Eller, B. H. Xie, J. Wang, H. T. Wu, J. Y. Li \& M. L. Zhao, 2020. Nitrogen input in different chemical forms and levels stimulates soil organic carbon decomposition in a coastal wetland. Catena 194: 104672.

Schimel, J. P., J. M. Gulledge, J. S. Clein-Curley, J. E. Lindstrom \& J. F. Braddock, 1999. Moisture effects on microbial activity and community structure in decomposing birch litter in the Alaskan taiga. Soil Biology \& Biochemistry 31(6): 831-838. 
Schjonning, P., I. Thomsen, P. Moldrup \& B. Christensen, 2003. Linking soil microbial activity to water- and air-phase contents and diffusivities. Soil Science Society of America Journal 67(1): 156-165.

Schlesinger, W. H. \& J. A. Andrews, 2000. Soil respiration and the global carbon cycle. Biogeochemistry 48: 7-20.

Shahzad, T., F. Anwar, S. Hussain, F. Mahmood, M. S. Arif, A. Sahar, M. F. Nawaze, N. Perveen, M. Sanaullah, K. Rehman \& M. I. Rashid, 2019. Carbon dynamics in surface and deep soil in response to increasing litter addition rates in an agro-ecosystem. Geoderma 333: 1-9.

Sinsabaugh, R. L., C. L. Lauber, M. N. Weintraub, B. Ahmed, S. D. Allison, C. Crenshaw, A. R. Contosta, D. Cusack, S. Frey, M. E. Gallo, T. B. Gartner, S. E. Hobbie, K. Holland, B. L. Keeler, J. S. Powers, M. Stursova, C. Takacs-Vesbach, M. P. Waldrop, M. D. Wallenstein, D. R. Zak \& L. H. Zeglin, 2008. Stoichiometry of soil enzyme activity at global scale. Ecology Letters 11(11): 1252-1264.

Six, J., R. T. Conant, E. A. Paul \& K. Paustian, 2002. Stabilization mechanisms of soil organic matter: implications for C-saturation of soils. Plant and Soil 241: 151-176.

Skopp, J., M. Jawson \& J. Doran, 1990. Steady-state aerobic microbial activity as a function of soil-water content. Soil Science Society of America Journal 54: 1619-1625.

Tao, B. X., Y. P. Wang, Y. Yu, Q. Z. Li, C. Y. Luo \& B. H. Zhang, 2018. Interactive effects of nitrogen forms and temperature on soil organic carbon decomposition in the coastal wetland of the Yellow River Delta, China. Catena 165: 408-413.

Tian, H. F., N. Huang, Z. Niu, Y. C. Qin, J. Pei \& J. Wang, 2019. Mapping winter crops in China with multi-source satellite imagery and phenology-based algorithm. Remote Sensing 11(7): 820-842.
Vesterdal, L., B. Elberling, J. R. Christiansen, I. Callesen \& I. K. Schmidt, 2012. Soil respiration and rates of soil carbon turnover differ among six common European tree species. Forest Ecology and Management 264: 185-196.

Vidon, P., S. Marchese, M. Welsh \& S. McMillan, 2016. Impact of precipitation intensity and riparian geomorphic characteristics on greenhouse gas emissions at the soil-atmosphere interface in a water-limited riparian zone. Water Air and Soil Pollution 227: 8.

Wang, J., C. Y. Wu, X. Y. Wang \& X. Y. Zhang, 2019. A new algorithm for the estimation of leaf unfolding date using MODIS data over China's terrestrial ecosystems. ISPRS Journal of Photogrammetry and Remote Sensing 149: 77-90.

Wong, K. K., 2013. Partial Least Squares Structural Equation Modeling (PLS-SEM) techniques using SmartPLS. Marketing Bulletin 24: 1-32.

Xu, X. G., H. P. Lin \& Z. Y. Fu, 2004. Probe into the method of regional ecological risk assessment - a case study of wetland in the Yellow River Delta in China. Journal of Environmental Management 70(3): 253-262.

Yin, S., J. H. Bai, W. Wang, G. L. Zhang, J. Jia, B. S. Cui \& X. H. Liu, 2019. Effects of soil moisture on carbon mineralization in floodplain wetlands with different flooding frequencies. Journal of Hydrology 574: 1074-1084.

Zhao, M. L., G. X. Han, J. Y. Li, W. M. Song, W. D. Qu, F. Eller, J. P. Wang \& C. S. Jiang, 2020. Responses of soil $\mathrm{CO}_{2}$ and $\mathrm{CH}_{4}$ emissions to changing water table level in a coastal wetland. Journal of Cleaner Production 269: 122316.

Publisher's Note Springer Nature remains neutral with regard to jurisdictional claims in published maps and institutional affiliations. 